\title{
EDITORIAL
}

\section{Corre, Antígona, corre}

\author{
Juan Jorge Michel Fariña* \\ Universidad de Buenos Aires
}

En Birdman, el premiado film de González Iñárritu, la misma escena teatral se juega tres veces. En la primera asistimos a la versión "oficial”, con los actores y sus respectivos parlamentos de acuerdo al guion. En la segunda se produce el acting que inesperadamente prolonga la escena fuera del teatro, con el actor obligado a ingresar a la sala en calzoncillos; la tercera vuelve al inicio y el elenco completo está en el escenario, pero el arma cargada introduce lo real que saca nuevamente la escena del teatro, esta vez de manera radical. ¿Qué nos dicen estas tres representaciones? Se trata de introducir un movimiento en el drama. A partir de la voladura de la nariz se aprecia la verdadera naturaleza trágica de la escena 1 (velada hasta entonces) y el sujeto puede finalmente saldar la impronta de su máscara. Atravesar su fantasma en ese Otro vuelo final, a la vez enigmático y revelador.

En el film polaco Przypadek ("El Azar", Kieslowsky, 1987), Witek, un estudiante de medicina que ha extraviado su vocación, se entera de la inminente muerte de su padre y va presuroso a sacar un pasaje para viajar a Varsovia y verlo antes del fin. Pero llega tarde a la estación y debe correr el tren, que ya comienza a alejarse del andén. A la manera de Corre, Lola, corre, ${ }^{1}$ Witek hará tres carreras diferentes para alcanzar desesperadamente el último vagón. En la primera logra abordar el tren. En la segunda es detenido por un guarda con quien tiene un altercado y termina en prisión. En la tercera, el tren se le escapa por un palmo de mano y queda desolado en la estación. A cada uno de los desenlaces sigue una historia diferente, de manera que el film se despliega en esas tres vidas divergentes. Vidas que son una misma pero vista desde distintas perspectivas. En las tres están presentes tanto la política como el amor, y toca a los espectadores juzgar las elecciones del personaje. Todo bajo el desquicio de la Polonia estalinista, ${ }^{2}$ para indicarnos con el giro final del argumento que el caos no puede ser suprimido sino como mucho suspendido, cada vez, en el instante de la decisión.
De alguna manera también esa es la estructura del film Remember, de Atom Egoyan, tal como aparece comentado por Eduardo Laso en su agudo artículo que integra este número de la revista. Zev Guttman emprende una travesía para encontrar y ajusticiar a un nazi llamado Rudy Kurlander, quien fue el asesino de su familia en el campo de concentración. Es instigado y guiado para ello por Max, otro viejo judío inválido con quien comparte la vida en un geriátrico. Pero ocurre que hay varios Rudy Kurlander en la guía telefónica, y hay que interrogar a cada uno para identificar al verdugo ¿Qué son los tres Kurlander con los que Zev se encuentra antes del fin, sino facetas de la pregunta que insiste dentro suyo? No meras variantes del tema de la venganza, sino tiempos lógicos para por fin comprender... y concluir.

Se trata de la cuestión de la tensión entre la memoria y el recuerdo, pero también de las vicisitudes del duelo. Por eso este número de la revista está modelado por el tema de la Antígona. No sólo de manera explícita en las sustanciales reseñas de Irene Cambra Badii y Paula Paragis, sino también en el comentario de Nuria Girona Fibla sobre el film El hijo de Saúl o en la memoria de Hiroshima, por Claudia Suárez.

Y por cierto también, entre líneas, en el artículo de Cristian Di Renzo sobre el film Mi mejor enemigo, ambientado en el conflicto armado entre Argentina y Chile por el Beagle, en la primavera de 1978. Conflicto que llegó a ser resuelto por vía pacífica, pero que retornó de manera desplazada y ominosa pocos años más tarde con la guerra de Malvinas. Una vez más, ¿qué tratamiento para los cuerpos en el campo de batalla?

Cuando Slavoj Zizek dice que apegarse a la letra tradicional es la manera más segura de traicionar el espiritu de una obra clásica, parece dar la razón al centenar de Antígonas recopiladas por George Steiner o a las cuatro decenas que agrega Rómulo Pianacci en su investigación sobre las variaciones latinoamericanas de la pieza de Sófocles. Siguiendo esta

* jjmf@psi.uba.ar 
línea, ¿podríamos imaginar nosotros una Antígona en Malvinas?

Inmediatamente después de la rendición de Puerto Argentino se planteó el problema de qué destino correspondía a los cuerpos de los soldados argentinos muertos en las islas. La primera iniciativa de los británicos fue la de "repatriar" los restos y enviarlos al continente. Pero ocurre que la Argentina reclamaba la soberanía sobre las Malvinas, y los soldados habían caído en lo que entendían era su patria. Fue así que las viudas, hijas, esposas de los soldados navegaron desde Comodoro para dar sepultura a sus hombres. Pero la expedición fue repelida por los ingleses y se les impidió desembarcar. Pasaron años hasta que por fin se estableció el cementerio de Darwin y los familiares pudieron llorarlos sobre un montículo de tierra, una lápida, un nombre y una cruz. ${ }^{3}$

Los tiempos del duelo son largos. Y también lentas sus inscripciones en la memoria colectiva. Allí una vez más, el cine viene en nuestra ayuda. Alain Resnais filmó Hiroshima mon amour a 15 años de la bomba, Tristán Bauer dejó su testimonio fílmico sobre el valor de la sepultura a 30 de Malvinas. ${ }^{4}$

Es que a la manera de Birdman, la historia se escribe en varias direcciones para poder ser contada. Solo así el sujeto puede finalmente inventarse en ella. Una vez más la verdad tiene estructura de ficción, lo cual significa que no se trata de historias paralelas o sucesivas: cada carrera de Lola, cada entrada en escena del actor en Birdman, cada corrida de Witak por alcanzar el tren, resultan retroactivamente performativas. Como los Kurlander en el periplo de Zev, no son errores o intentos fallidos, sino asertos de certidumbre anticipada que configuran el valor, último y primero, de una decisión.

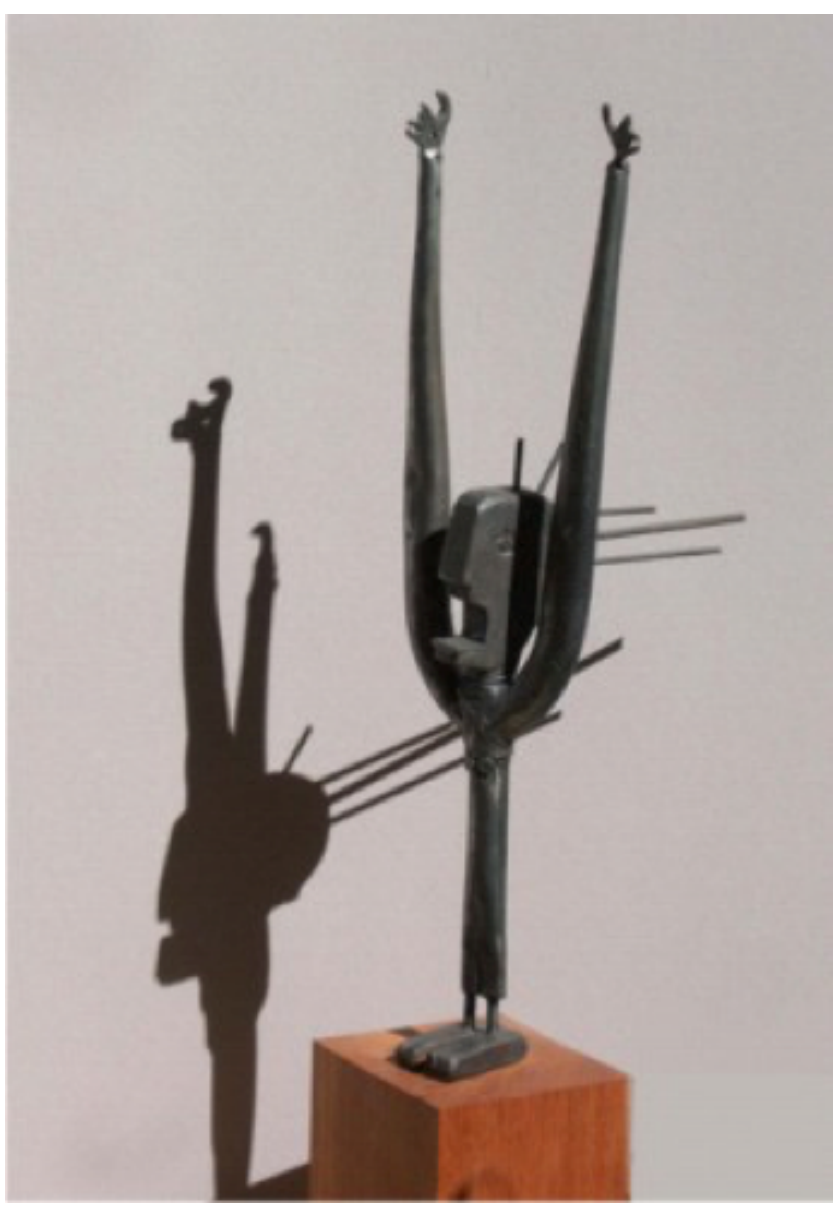

Gustavo Rodríguez. Antígona. Escultura en hierro, año 2010.

\footnotetext{
1 En Corre, Lola, corre (Run Lola Run, Tom Tykwer, 1998), Lola recibe un llamado telefónico de su novio, quien ha perdido accidentalmente 100.000 Marcos que pertenecen a un traficante. Si no consigue el dinero en 20 minutos, es hombre muerto. Ella promete encontrarse con él para ayudarlo a resolver el problema, aunque no tiene la menor idea de cómo hacerlo... Inicia una carrera hasta el lugar de la cita, pero llega tarde y ya su novio, desesperado, está asaltando una tienda. Ella intenta intervenir y muere asesinada por un policía. La secuencia comienza nuevamente, pero en esta segunda carrera Lola evita algunos obstáculos para llegar antes a su cita. Lo logra, pero esta vez es su novio quien muere atropellado. Vuelta a comenzar, y en su tercera carrera Lola hace una pausa para encomendarse a la diosa Tyché: entra a un casino y apuesta en la ruleta, ganando el dinero necesario para resolver el problema. Pero su cambio de itinerario alteró los hechos, introduciendo nuevas variantes en la historia, con un giro final que no adelantaremos aquí. Inspirada en la teoría del caos y el "efecto mariposa”, la película trata sobre el azar, el destino y sobre todo la contingencia en las elecciones del sujeto. En esta última línea es donde se recortan las escenas clave del film, en las que se va modelando la posición de Lola en relación a su deseo. Se trata del objeto de amor, jugado entre el padre y el amante, imprevistamente anudados en la peripecia situacional. Sobre la relación de este film con la Antigone de Slavoj Zizek, ver la reseña de Paula Paragis en este volumen de Etica\&Cine.
}

2 Si bien el film fue realizado en 1981, su estreno debió esperar hasta 1987 debido a la fuerte censura estatal que objetó su contenido político.

3 Esta gesta está narrada en varios filmes y documentales sobre Malvinas, especialmente en Iluminados por el fuego (Tristan Bauer, 2005), El pulover azul (2012), entre muchos otros que escribieron, en la filigrana del cine, la vigencia del texto de Sófocles.

$4 \quad$ Por eso no hay un film paradigmático sobre la guerra, sino fragmentos, cortos. Y a veces esas pinceladas singulares dan mejor la medida que las grandes épicas. Volviendo a los rituales funerarios y la cuestión del deseo, el homenaje al monólogo de Hamlet por Hugh Grant, en el film Florence, de Stephen Frears, o el de Colin Firth en El discurso del Rey, o el más sublime de todos, el de Ernst Lubitch en su comedia negra de 1942 Ser o no ser, son unos pocos ejemplos de ello. 